\title{
Evaluation of Sand-Shell Mixture Behaviour for Breakwater Foundation
}

\author{
Abbass Tavallali ${ }^{1}$, Justine Mollaert ${ }^{2}$ \\ International Marine and Dredging Consultants, Antwerp, Belgium \\ E-mails: 'Iabbass.tavallali@imdc.be (corresponding author); ${ }^{2} j u s t i n e . m o l l a e r t @ i m d c . b e$
}

\begin{abstract}
The available sand material for a breakwater foundation is mixed with shells. The shell percentage of the sand material is variable and percentages up to even $50 \%$ are observed. It is essential to evaluate the properties and the behaviour of the sand-shell mixture as this will form the improved breakwater foundation. In reality the backfilled sand of the breakwater foundation has different relative densities in different depths. In this study the mechanical properties of the sand-shell mixture for different relative densities are evaluated. For different relative densities of sand-shell mixture the direct shear tests and the consolidated undrained triaxial tests are carried out on some samples. The results of the experiments showed that the samples with higher relative density show a higher internal friction angle. However, for the samples with even low relative density, an internal friction angle of less than $32^{\circ}$ is not observed. The volume variation of the samples with different relative densities are monitored. Samples with low relative density showed a contraction behaviour; resulting in an increase of the pore water pressure, a reduction of the effective strength and finally the samples become susceptible to liquefaction. While the samples with high relative density showed a dilatancy behaviour.
\end{abstract}

Keywords: breakwater foundation improvement, dredging, relative density, sand friction angle, sand-shell mixture, shell content, soft soil.

Conference topic: Soil and rock investigation.

\section{Introduction}

An offshore breakwater is designed for the construction of a LNG-terminal. Based on the geotechnical investigation, it is understood that the breakwater foundation consists of layers from very soft soil (on top) to resistant sediments (at greater depth). The top layer is soft soil consisting of a high plasticity clay. The $\mathrm{N}$ value of SPT (standard penetration test) for this layer is zero. It means that the soil materials at the location of the breakwater foundation is very soft and does not have the appropriate bearing capacity. Consequently, the top layer should be removed or improved.

Several methods for soil improvement were studied (e.g. preloading and drainage, geo-fabrics, in-situ soil mixing and stone columns). It is understood that the soil improvement methods are not appropriate for the site of the LNG-terminal. However, it should mention that in encountering peat or soft soil deposits, the most common solution is to excavate the peat or soft soil and replace it with the fill material with good mechanical properties. This solution is only prohibited if the peat deposit is so deep or if satisfactory fill material is not available. The thickness of the soft soil in the project is $16 \mathrm{~m}$ to $22 \mathrm{~m}$ and sand material in a borrow area near the site is available as well. Therefore, it is decided and designed to remove the top poor layer (the soft soil consisting of a high plasticity clay) and replace it with backfill material of good mechanical properties.

The sand materials in the available borrow area are mixed with shells. The shell percentage of the sand materials is variable and percentages up to even $50 \%$ are observed. In other words the available sand is a het- erogeneous mixture. The effect of heterogeneity on mechanical properties of geomaterials is more than one would expect from the percentage of the heterogeneity. So the shell content of the sand material should be considered as an important factor.

The sand materials in different projects and studies are different (calcareous or silica sand). Appling the data from the literature cannot be necessarily representative for the existing specific sand mixture. Therefore, in order to understand the mechanical properties and behaviour of the specific sand mixture of the project site, geotechnical studies are needed.

In another words, it is essential to evaluate the properties and the behaviour of the sand-shell mixture (of the borrow area) as this will form the improved foundation of the breakwater. In this paper the mechanical properties of the sand-shell mixture are investigated. It should also be indicated that the breakwater foundation after the improvement becomes a permeable foundation. Pore water pressure variations occur due to the present wave climates and its effect should be considered for the slope stability analysis of the breakwater (Mollaert, Tavallali 2016).

\section{Material}

The sand backfill material is sourced from a borrow area, which is located approximately $35 \mathrm{~km}$ from the project site. The borrow area is extended in an approximately rectangular shape about $1.5 \mathrm{~km}$ by $4 \mathrm{~km}$. In order to be able to evaluate the behaviour of sand backfill material, some representative samples from the material are needed. Two main sampling campaigns for the sand 
materials are carried out. The first sampling campaign is a 9-day campaign onboard the trailing suction hopper dredger (TSHD) during which 66 samples (see Fig. 1) are taken from different hopper loads (of the material dredged from borrow area and transferred to breakwater foundation).

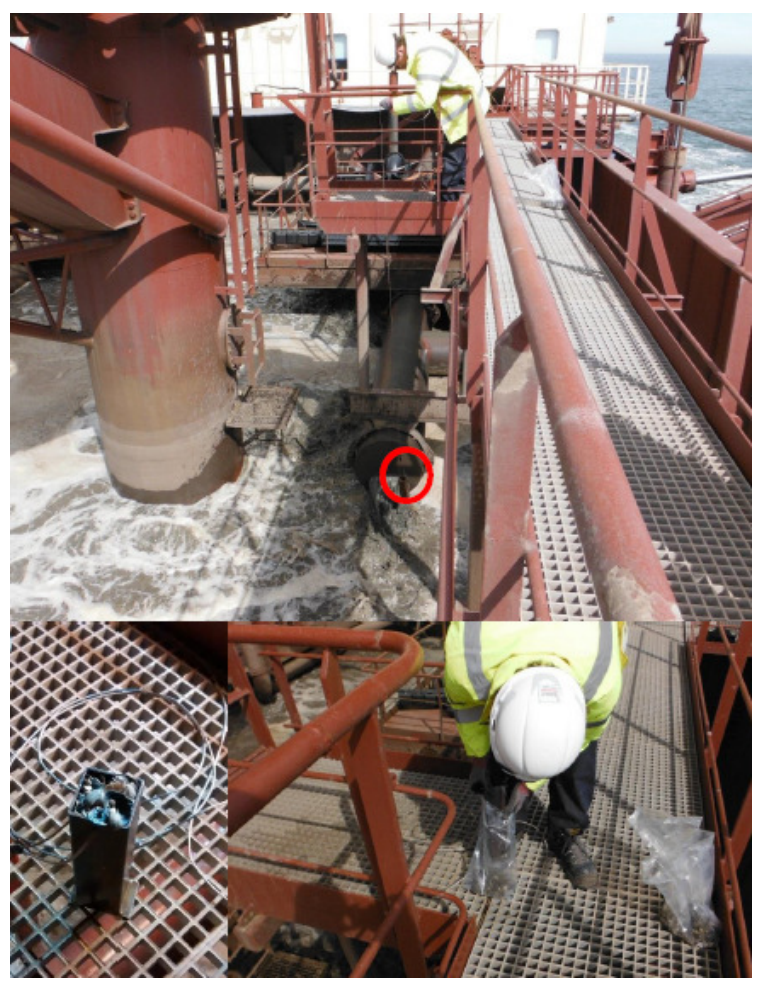

Fig. 1. The samples from TSHD were taken directly under the hopper intake valve. Sampler is indicated by a red circle and also presented in the left bottom of the figure

The second sampling campaign was a combination of shallow (Van Veen) and deep (vibrocore) sampling in the borrow area. A vibrocore campaign for deep soil sampling is executed in two days. Purpose of the campaign is to get a better insight into the characteristics of the borrow area over a greater depth. In total 20 vibrocore tubes are taken. 20 superficial samples are also taken with a Van Veen grab at different points in the borrow area. The samplers in the second campaign are presented in Figure 2. By looking at the different samples taken from the sampling campaigns, it was observed that the borrow area contains a heterogeneous sand-shell mixture.

The percentage of the shell in different samples (shell content) showed a high variations even by visual observation. It is confirmed later by the laboratory experiments as well. In Figure 3, some samples from the sampling campaigns are presented. The different shell contents in different samples taken from the trailing suction hopper dredger and also the Van Veen samples are clearly remarkable. It can be concluded that shell content is variable in different locations of borrow area. Looking at the vibrocore samples showed that even in one location the shell content variation exits in different depths (see the bottom photo in Fig. 3). It means that the borrow area has a heterogeneous sand-shell mixture in different locations and also in different depths. It is not possible to consider a location in the borrow area where the sand material has less shell content in a specific depth.
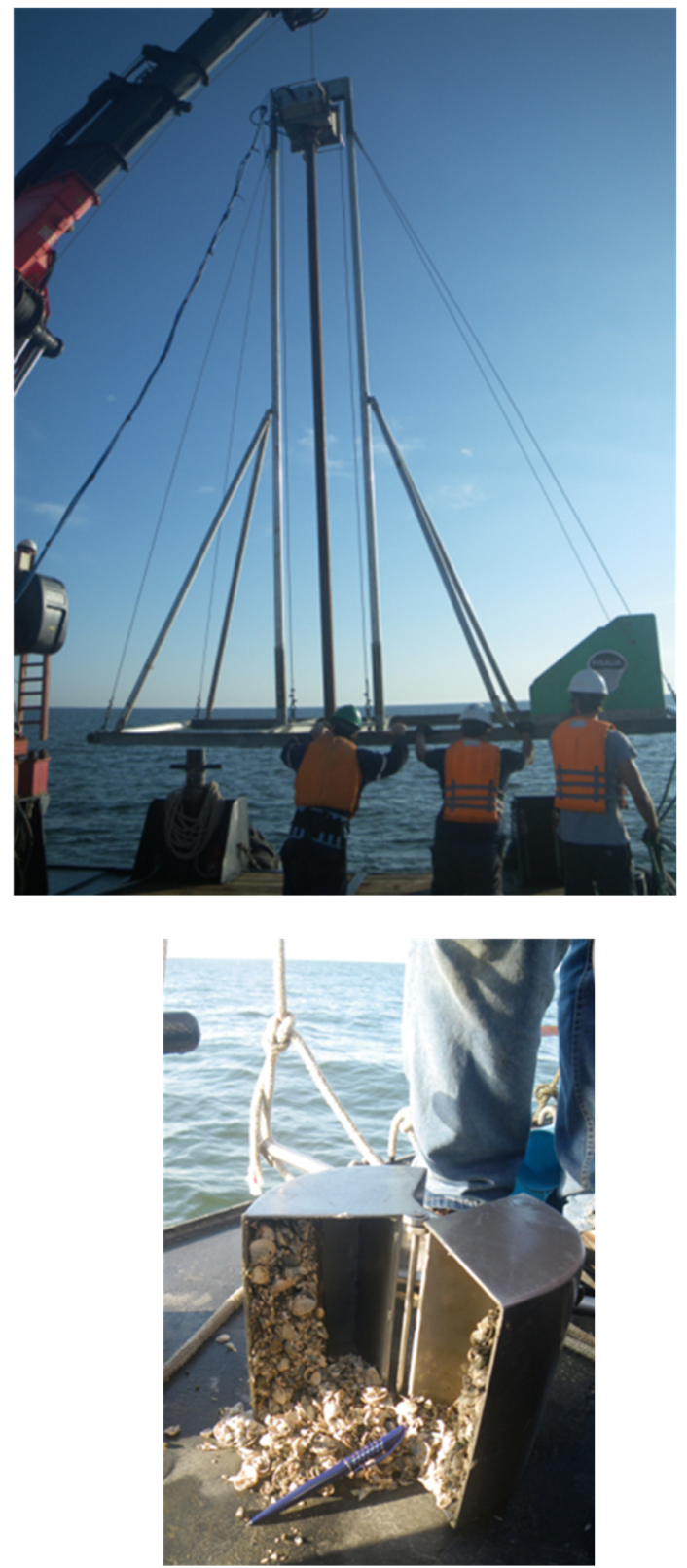

Fig. 2. Top: The applied vibrocore system, by using a $6 \mathrm{~m}$ penetration tube. Bottom: Van Veen sampler, the dimension of each bucket is $11.5 \times 20.5 \mathrm{~cm}$

In this projects two TSHDs with different hopper size are used to bring the sand material from borrow area to the breakwater foundation. Also the sand placement methods are different. In the deeper part of the foundation trench, the dumping method is used. In this 

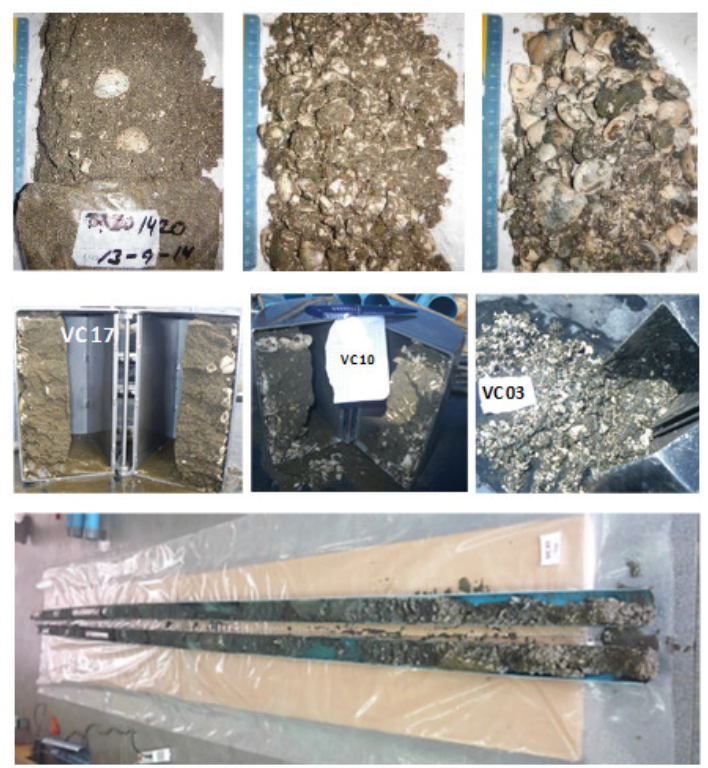

Fig. 3. Some samples from two sampling campaigns. Top: samples taken from the trailing suction hopper dredger. Middle: samples taken by Van Veen. Bottom: a vibrocore sample

method a huge amount of sand (e.g. $\left.6000 \mathrm{~m}^{3}\right)$ is dumped all at once as a whole. However, for the (shallow) top parts of the foundation trench, the hopper is evacuated gradually (due to the draft limitation of the ships). The sand materials in the breakwater foundation disposed by the two mentioned placement methods have different relative densities (Van 't Hoff, Van der Kolff 2012). As in reality the backfilled sand has different relative densities in different depths, in this study the mechanical properties of the sand-shell mixture for different relative densities are investigated.

\section{Performed experiments}

From the taken samples some laboratory experiments are executed to evaluate the mechanical properties of the sand-shell mixture. The following experiments are conducted: grain size distribution, minimum and maximum density, carbonate content, visual inspection of shell content, direct shear test and consolidated undrained triaxial test. Two shear boxes with the size of $100 \times 100 \mathrm{~mm}$ and $60 \times 60 \mathrm{~mm}$ are applied for the direct shear tests. The applied triaxial apparatus has the diameter of $50 \mathrm{~mm}$. Different relative densities of sand-shell mixture are considered for the direct shear tests and for the consolidated undrained triaxial tests.
A combination of vibrocore samples and samples taken from the hopper are analysed at a laboratory in Belgium. Several of the taken sand samples are mixed first (as in reality) to have a representative sample. Representative samples are chosen following the quartering method to determine the minimum and maximum density and for the sieving analysis. For the experiments the samples are prepared by reconstituting the same grain size distribution for all samples (in order to be able to compare the results).

Due to different sizes of the apparatus available in laboratory, samples with different fractions are prepared in order to eliminate the size effect anomalies of large particles on the whole sample properties. For this purpose, the largest grain size in the sample shall not be greater than 1/6 times the apparatus length or diameter. For the direct shear box with the size of $100 \times 100 \mathrm{~mm}$, the samples were prepared from the fraction passing the $16 \mathrm{~mm}$ sieve $(100 / 6=16.7 \mathrm{~mm})$. For the other direct shear box with the size of $60 \times 60 \mathrm{~mm}$ and the triaxial apparatus with the diameter of $50 \mathrm{~mm}$, the samples are prepared from the fraction passing the $8 \mathrm{~mm}$ sieve $(50 / 6=8.3 \mathrm{~mm})$.

\section{Tests results and discussions}

In this part the tests results of each experiments are shortly presented and discussed.

\section{Grain size distribution}

The grain size distribution test is performed according to the standard ASTM D422. As the particles size smaller than $75 \mu \mathrm{m}$ is less than $10 \%$ only the sieving method is applied (and using a hydrometer is not needed). The sieving analysis is done for the whole sample as well as for the fraction smaller than $16 \mathrm{~mm}$ and smaller than $8 \mathrm{~mm}$ (see Table 1). Apart from the whole sample, for each fraction two samples are tested and the variations are indicated in Table 1 . The results show that the size ranges of the two samples from each fraction are consistent and the differences are marginal. The specified size ranges in the mentioned table are based on the British Standards (Craig 2004).

By visual observation of the remaining particles on the sieves, it is understood that the large particles (classified as coarse sand and gravel) are mainly shells. Consequently, based on the results presented in Table 1 and the mentioned visual observation, it can be concluded that the sand part of the mixture is fine to medium sand $(0.063-0.6 \mathrm{~mm})$ and larger particles are mainly shells.

Table 1. Grain size distribution of the whole sample as well as for the fraction smaller than $16 \mathrm{~mm}$ and smaller than $8 \mathrm{~mm}$. For each fraction two samples are tested and the variations are indicated

\begin{tabular}{l|c|c|c|c}
\hline \multirow{2}{*}{$\begin{array}{r}\text { Particles } \\
\text { Sample }\end{array}$} & $<0.063 \mathrm{~mm}$ & $0.063-0.2 \mathrm{~mm}$ & $0.2-2 \mathrm{~mm}$ & $2-60 \mathrm{~mm}$ \\
\cline { 2 - 5 } & Fine particles (silt and clay) & Fine sand & Medium to coarse sand & Gravel \\
\hline Whole & $2.2 \%$ & $31.4 \%$ & $44.3 \%$ & $22.1 \%$ \\
\hline$<16 \mathrm{~mm}$ & $1.5-2.0 \%$ & $29.7-31.9 \%$ & $41.5-44.6 \%$ & $21.5-27.3 \%$ \\
\hline$<8 \mathrm{~mm}$ & $1.9-2.4 \%$ & $32.7-33.0 \%$ & $49.3-51.0 \%$ & $14.4-15.3 \%$ \\
\hline
\end{tabular}


Table 2. Minimum and maximum densities for different samples. The carbonate content for the whole sample as well as for the fraction smaller than $16 \mathrm{~mm}$ and smaller than $8 \mathrm{~mm}$ is also indicated

\begin{tabular}{l|c|c|c}
\hline Maximum grain size & Minimum density $\left(\mathrm{kg} / \mathrm{m}^{3}\right)$ & Maximum density $\left(\mathrm{kg} / \mathrm{m}^{3}\right)$ & Carbonate content (\%) \\
\hline $60 \mathrm{~mm}($ whole $)$ & 1516 & 2028 & 27.9 \\
\hline $16 \mathrm{~mm}$ & 1555 & 2036 & 24.3 \\
\hline $8 \mathrm{~mm}$ & 1548 & 1958 & 23.9 \\
\hline $5 \mathrm{~mm}$ & 1656 & 1838 & - \\
\hline
\end{tabular}

\section{Minimum and maximum density}

The minimum and maximum densities are determined for the whole sample, fraction smaller than $16 \mathrm{~mm}$, fraction smaller than $8 \mathrm{~mm}$ and also the fraction smaller than $5 \mathrm{~mm}$. The reason why a sample is prepared from the fraction passing the $5 \mathrm{~mm}$ sieve is to investigate the shell size effect (which is explained later). The results of the minimum and maximum densities for each sample are presented in Table 2 .

The minimum density represents the loosest condition of a cohesionless free draining soil. The minimum density is determined following the standard ASTM D4254 by preventing bulking, particle segregation and minimising compaction of the sample. On the other hand the maximum density is measured using the vibrating table (following ASTM 4253), but no load is applied in order to avoid particle crushing.

\section{Carbonate content}

For carbonate content measurements the hydrochloric acid $(\mathrm{HCl})$ is applied. The carbonate content of the samples is estimated as the percentage of dry mass lost after reacting with the solution of $\mathrm{HCl}$. The results of carbonate content for the whole sample as and for the fraction smaller than $16 \mathrm{~mm}$ and smaller than $8 \mathrm{~mm}$ are indicated in Table 2. As can be observed as the maximum grain size in the samples becomes smaller the carbonate content decreases. It is in agreement with the visual observation of the samples, which indicates the larger (than $0.6 \mathrm{~mm}$ ) particles are mainly shells. As the larger parts are removed more shells are removed and consequently lower values for carbonate content is achieved.

A sand is classified as a carbonate sand if its carbonate content is higher than $90 \%$; while, a siliceous carbonate sand has a carbonate content of $50 \%$ to $90 \%$ (Clark, Walker 1977; Meigh 1987). Mentioned classification idea is later confirmed in the book "cone penetration testing in geotechnical practice" (Lunne et al. 1997). It is mentioned that the soils with carbonate contents of less than $50 \%$ to $70 \%$ behave similar to the noncalcareous soils and the carbonate grains play a less important role in the engineering response (Lunne et al. 1997).

Based on the available information and the presented test results, it can be concluded that sand materials which are used for the soil replacement in the breakwater foundation is considered as silica sand with shells.

\section{Direct shear test}

Two different apparatus of direct shear tests with the box size of $100 \times 100 \times 26 \mathrm{~mm}$ and $60 \times 60 \times 30 \mathrm{~mm}$ are applied. Three different consolidated pressures $(50 \mathrm{kPa}$, $100 \mathrm{kPa}$ and $150 \mathrm{kPa}$ ) for the tests are applied. In order to achieve the most uniform sample quality, for the sample preparation the method using undercompaction has been followed (Ladd 1978). However, the method can strictly not be followed as the sample is prepared in one layer.

In order to avoid the shell crushing effect, the three different consolidated pressures are not applied on one sample. Also after the tests, the tested samples were verified. Shell crushing for at least large shells was not observed and the crushing is considered to be marginal.

At first the results from the small box of $60 \times 60 \times 30 \mathrm{~mm}$ are presented. The direct shear tests are carried out for three different relative densities, namely $25 \%, 40 \%$ and $75 \%$. The applied deformation rate is $0.07 \mathrm{~mm} / \mathrm{min}$. In the tested samples, the dry density of the samples varies from $1630 \mathrm{~kg} / \mathrm{m}^{3}$ to $1840 \mathrm{~kg} / \mathrm{m}^{3}$; which correspond to the relative density of $25 \%$ to $75 \%$, respectively.

Table 3. Results of the direct shear tests $(60 \times 60 \times 30 \mathrm{~mm})$. The tested samples are prepared from the fraction passing of $8 \mathrm{~mm}$ sieve

\begin{tabular}{c|c|c}
\hline Relative density & Friction angle & Sample behaviour \\
\hline $25 \%$ & $32.2^{\circ}$ & Contract (compact) \\
\hline $40 \%$ & $34.2^{\circ}$ & Contract (compact) \\
\hline $75 \%$ & $36.4^{\circ}$ & Dilate (expand) \\
\hline
\end{tabular}

The results of the direct shear tests $(60 \times 60 \times 30 \mathrm{~mm})$ are presented in Table 3 . The applied samples are prepared from the fraction passing the $8 \mathrm{~mm}$ sieve. It can be concluded from the presented results that for different relative densities from $25 \%$ to $75 \%$, always the internal friction angle is larger than $32^{\circ}$. It is also observed that the samples with higher relative density show a higher internal friction angle. The friction angle of the sample with low relative density $(25 \%)$ is $32^{\circ}$; while, it becomes $36^{\circ}$ for the sample with high relative density $(\mathbf{7 5 \%})$.

The sample behaviour and the volume change during the tests are also monitored. It is observed that the behaviour of samples with different densities are not similar. As presented in Table 3, the samples with low relative densities are contracted (compacted) during the 
tests (and mainly before the failure). The sample contraction is illustrated in the top diagram presented in Figure 4. As it can be seen the height of the sample is reduced and the compaction for the consolidated pressure of $150 \mathrm{kPa}$ is continued up to the end of the test. However, it should be mentioned that in the presented test (relative density $25 \%$ ), before $2 \mathrm{~mm}$ of applied horizontal deformation the sample resistance converge to its residual resistance. In other words the focus is on the first $2 \mathrm{~mm}$ part of the test where the contraction behavior is observed. The sample contraction means the reduction in sample volume; which increases the pore water pressure. The excess pore water pressure, reduces the effective strength of the samples. Consequently the samples become susceptible to be liquefied.

On the other hand, the samples with high relative density (75\%) shows a dilatancy behaviour (see the bottom diagram in Figure 4). The mentioned samples expanded during the test (and mainly before the failure). The volume expansion increases the effective strength of the sample and it stays rigid.

In the second step, the results from the larger box $(100 \times 100 \times 26 \mathrm{~mm})$ on samples at two relative densities $(0 \%$ and $40 \%)$ are presented. For the mentioned sample of $0 \%$ relative densities, a low value of saturation during sample preparation is selected to allow pouring the material into the mould that results in the lowest possible relative density. However, after saturation and consolidation, the sample height reduces and results in an increase in relative density. The applied deformation rate is $1 \mathrm{~mm} / \mathrm{min}$.

The results of the direct shear box tests $(100 \times$ $100 \mathrm{~mm}$ ) are presented in Table 4. The applied samples are prepared from the fraction passing the $16 \mathrm{~mm}$ sieve. However, a sample prepared from the fraction passing the $5 \mathrm{~mm}$ sieve is also tested.

It can be concluded from Table 4 that for different relative densities from $0 \%$ to $40 \%$, always the internal friction angle is larger than $42^{\circ}$. It is also observed that the samples with higher relative density show a higher internal friction angle. The friction angle of the sample with zero relative density is $42.5^{\circ}$; while it becomes $51^{\circ}$ for the sample with $40 \%$ relative density. The results from both direct shear test apparatus are compatible with each other. The reason that with larger apparatus, higher friction angles are achieved is the application of higher deformation rate (Mamo, Dey 2014).
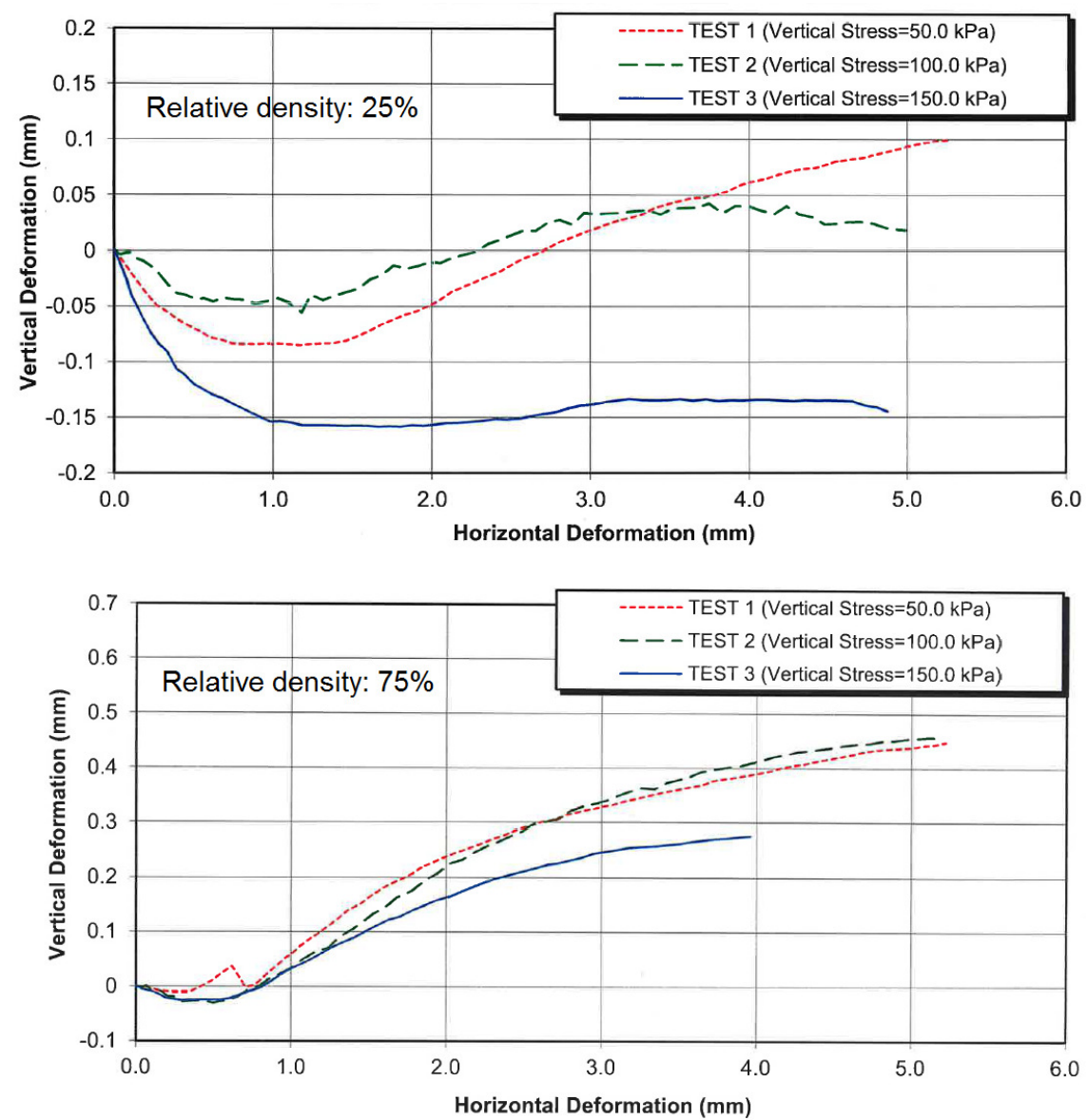

Fig. 4. Sample behaviour in direct shear tests $(60 \times 60 \mathrm{~mm})$ in three different consolidated pressures $(50 \mathrm{kPa}, 100 \mathrm{kPa}$ and $150 \mathrm{kPa}$ ). The top diagram shows the contract (compaction) behaviour of the samples with low relative density $(25 \%)$. The bottom diagram shows the dilatancy behaviour of the samples with high relative density $(75 \%)$ 
Table 4 . Results of the direct shear tests $(100 \times 100 \times 26 \mathrm{~mm})$. The tested samples are prepared from the fraction passing of $16 \mathrm{~mm}$ and $5 \mathrm{~mm}$ sieves

\begin{tabular}{c|c|c}
\hline $\begin{array}{c}\text { Maximum grain size - } \\
\text { Relative density }\end{array}$ & $\begin{array}{c}\text { Friction } \\
\text { angle }\end{array}$ & Sample behaviour \\
\hline $16 \mathrm{~mm}-0 \%$ & $42.5^{\circ}$ & Contract (compact) \\
\hline $16 \mathrm{~mm}-0 \%$ & $43.0^{\circ}$ & Contract (compact) \\
\hline $16 \mathrm{~mm}-40 \%$ & $51.0^{\circ}$ & Contract - Dilate \\
\hline $5 \mathrm{~mm}-13 \%$ & 44.5 & Contract - Dilate \\
\hline
\end{tabular}

Similar to the previous direct shear test results, the volume change behaviour is not the same for samples with different densities. The results presented in Table 4 show that the samples with low relative densities are contracted (compacted) during the tests (this happens mainly before the failure) and samples become susceptible to liquefaction.

The last two samples presented in Table 4 ( $16 \mathrm{~mm}-40 \%$ and $5 \mathrm{~mm}-13 \%$ ) have different relative densities after preparation. However, after saturation and consolidation process, their relative densities became closer to each other $(45 \%$ for the sample $16 \mathrm{~mm}-$ $40 \%$ and $33 \%$ for the sample $5 \mathrm{~mm}-13 \%$ ). The sample volume change for the two samples with medium relative density, shows a small contraction and then a dilatancy behaviour. The relative density condition of the two mentioned samples is in the limit to be liquefied (i.e. critical point). In other words, for the lower relative densities a risk of liquefaction is dominant; while, for the higher relative densities the condition is safe and stable. Another important observed subject is that the sample contraction in the finer sample $(5 \mathrm{~mm}-13 \%)$ is less than the contraction in coarser sample $(16 \mathrm{~mm}-$ $40 \%$ ). The main difference of the two samples is the shell size. As expected, the sample with larger shells has higher volume contraction due to the compression. So, it can be concluded that in real conditions with much larger shells, the risk of soil contraction and consequently liquefaction are higher.

\section{Consolidated undrained triaxial test}

The consolidated undrained triaxial testing is executed at three effective consolidation pressures $(50 \mathrm{kPa}$, $100 \mathrm{kPa}$ and $200 \mathrm{kPa}$ ) and at three relative densities $(15 \%, 40 \%$ and $70 \%)$. The applied deformation rate is $0.2 \mathrm{~mm} / \mathrm{min}$. The tested samples are prepared from the fraction passing the $8 \mathrm{~mm}$ sieve. To have most uniform sample quality, undercompaction method for sample preparation has been followed (Ladd 1978). In order to improve the saturation phase, the sample is flushed with $\mathrm{CO}_{2}$ prior to sample saturating. The voids filled with $\mathrm{CO}_{2}$ tend to be easier replaced with water during the saturation phase than air-filled voids.

In the tested samples, the dry density of samples varies from $1570 \mathrm{~kg} / \mathrm{m}^{3}$ to $1800 \mathrm{~kg} / \mathrm{m}^{3}$. The results of the consolidated undrained triaxial test $(50 \mathrm{~mm}$ diameter and $92.5 \mathrm{~mm}$ height) are presented in Table 5 . It can be concluded from Table 5 that for different relative densities from $7 \%$ to $63 \%$, the internal friction angle is always larger than $33^{\circ}$. It is also observed that the samples with higher relative density show a higher internal friction angle. The friction angle of the sample with low relative density (around $10 \%$ ) is $33^{\circ}$; while, it becomes $38^{\circ}$ for the sample with high relative density (around $70 \%)$.

Table 5. Results of the consolidated undrained triaxial test (50 $\mathrm{mm}$ diameter and $92.5 \mathrm{~mm}$ height). The tested samples are prepared from the fraction passing of $8 \mathrm{~mm}$ sieves

\begin{tabular}{c|c|c}
\hline Relative density & Friction angle & Sample behaviour \\
\hline $7 \%$ & $33.0^{\circ}$ & Contract (compact) \\
\hline $43 \%$ & $36.0^{\circ}$ & Contract - Dilate \\
\hline $63 \%$ & $38.0^{\circ}$ & Dilate (expand) \\
\hline
\end{tabular}

Similar to previous laboratory test results, the sample volume change behaviour is not the same for samples with different densities. The results presented in Table 5 show that samples with low relative densities are contracted (compacted) during the tests (and mainly before the failure). In this condition, as already explained, the samples become susceptible to liquefaction.

The volume change for the sample with medium relative density, shows a small contraction and then a dilatancy behaviour. The relative density of the mentioned sample is in the limit of liquefaction (i.e. critical point). In other words, for lower relative densities a risk of liquefaction is dominant; while, for higher relative densities the condition is safe and stable.

The sample with high relative density (around $70 \%$ ) shows a dilatancy behaviour. The mentioned sample expanded during the test (and mainly before the failure). The volume expansion induces some negative pore water pressure and consequently the effective strength of the sample increases. In this condition the sample stays rigid.

\section{Discussions and conclusions}

It is noticed from the different witnessing campaigns that the backfill material is quite heterogeneous and a considerable difference in shell percentage (roughly from about $0 \%$ to $50 \%$ ) is observed over the different samples that are taken. In the mentioned samples the percentage of fines is marginal. The direct shear tests and the consolidated undrained triaxial tests are executed on the sand-shell mixture and the following conclusions are achieved:

- The achieved friction angle is always higher than the $32^{\circ}$ and increases with increasing the relative density.

- For samples with low and medium relative densities (up to $45 \%$ ) the volume is decreased during the tests. This indicates that for these relative densities, the soil is potentially subject to liquefaction. The total volume decreases, so the 
void volume decreases too. Then the pore water pressure is increased and will reduce the effective stress. In the case that the effective stress goes to zero, the foundation material acts similar to the liquid.

- For samples with higher relative densities (70\%) the sample volume after a marginal decrease starts to increase. The increase of the volume causes a negative pore water pressure. The negative pressure induces an internal attraction force between the grains and consequently the material stays rigid.

- The decreasing rate of the sample volume seems increasing when the shell size is bigger (meaning that shells can increase the liquefaction risk).

The final item that should be indicated concerns the areas of the sand-shell mixture that are susceptible for liquefaction (due to earthquake or wave action). These areas should be identified by for example a verification CPT (Cone Penetration Test) campaign on backfilled sand-shell mixture. Verification CPT campaign gives the cone resistance and the density of the sand-shell mixture. The areas with low resistance that has low density will be indicated. These areas should be compacted. The compaction of low density sand-shell mixture increases the density of the mixture and consequently eliminates the risk of the foundation failure (due to liquefaction). In other words based on the presented results in this article the sand-shell mixture with low relative density should be compacted to change to medium to high relative density (that has no liquefaction risk). The information presented in this paper tries to give a better understanding about the sand-shell mixture behaviour. It can help during the verification process of the breakwater foundation improved by the sand-shell mixture in order to judge if the compaction is necessary.

\section{Acknowledgements}

Authors acknowledge their sincere thanks to professor Jan Maertens for his helpful comments. Thanks to Michiel Goossens for taking and analysing the samples from the sampling campaign onboard the TSHD.

\section{References}

ASTM standard D422. Standard test method for particle-size analysis of soils, ASTM International, West Conshohocken, PA, 2007.

ASTM standard D4253. Standard test methods for maximum index density and unit weight of soils using a vibratory table. ASTM International, West Conshohocken, PA, 2015.

ASTM Standard standard D4254. Standard test methods for minimum index density and unit weight of soils and calculation of relative density. ASTM International, West Conshohocken, PA, 2015.

Clark, A. R.; Walker, B. F. 1997. A proposed scheme for the classification and nomenclature for use in the engineering description of Middle Eastern sedimentary rocks, Geotechnique 27(1): 93-99. http://dx.doi.org/10.1680/geot.1977.27.1.93

Craig, R. F. 2004. Craig's soil mechanics. $7^{\text {th }}$ ed. Spon Press.

Ladd, R. 1978. Preparing test specimens using undercompaction, Geotechnical Testing Journal 1(1): 16-23. http://dx.doi.org/10.1520/GTJ10364J

Lunne, T.; Robertson, P. K.; Powell, J. J. M. 1997. Cone penetration testing in geotechnical practice. $1^{\text {st }}$ ed. Taylor \& Francis.

Mamo, G. B.; Dey, A. 2014. Critical overview of the effect of strain rate on direct shear test results, in North East Students Geo-congress on Advances in Geotechnical Engineering, 18 October 2014, Guwahati, India.

Meigh, A. C. 1987. Cone penetration testing: methods and interpretation. CIRIA ground engineering report: In-situ testing. Butterworths, London.

Mollaert, J.; Tavallali, A. 2016. Including the influence of waves in the overall slope stability analysis of rubble mound breakwaters, in $13^{\text {th }}$ Baltic Sea Geotechnical Conference, 22-24 September 2016, Vilnius, Lithuania.

Van 't Hoff, J.; Van der Kolff, A. N. 2012. Hydraulic Fill Manual: For Dredging and Reclamation Works. $1^{\text {st }}$ ed. CRC Press. 